\title{
The Face Recognition Technology in the Shanghai Disneyland
}

\author{
Yan Zhang, Dong Xie
}

\author{
Information School, Hunan University of Humanities, Science and Technology \\ Loudi, China
}

\begin{abstract}
Face recognition is a new biometric identification technology that has emerged in recent years with the rapid progress of modern achievements such as computer technology, image processing technology and pattern recognition technology. The applications of this technology in urban security precautions have greatly improved the practical effects of security works. How to combine the social security of Disneyland and accelerate the application of urban surveillance is very meaningful.
\end{abstract}

Keywords: Shanghai, Disneyland, Safety, Face recognition

\section{Introduction}

In recent years, China's social and economic development has developed rapidly. After the opening of large-scale amusement parks in cities such as changlong and Disney, a large number of tourists came to the city every day, bringing with them a growing security problem. In order to hit the national separatism and terrorist attacks at home and abroad, dealing with all kinds of economic crime, protect national and people's life and property security, ensure all walks of life and the normal operation of city key department, using high-tech security technology to prevent and stop the crime has become the urgent demand of "safe city" construction [1].

With the introduction of various new security concepts abroad, all walks of life have started to establish CCTV system or alarm system[2]. Especially in banking, communications, postal savings, electricity, Internet cafes and other places, we have established a networked alarm system, which has played a major role in preventing and preventing crime and maintaining social stability [3].

However, the digital surveillance system currently used by Banks, public security and government agencies only has the function of general surveillance and recording. Most of them are single-machine operation, video data is not easy to read, and cannot be centralized management and maintenance. Meanwhile, it is difficult to accurately dial the facial features of the object, causing the delay of the investigation. The most important thing is that the existing massive video data lacks intelligent and fast retrieval methods, so that the monitoring system cannot meet the user's higher requirements.

In this study, Disney theme park in mainland China is taken as the object to apply the new technique in the security management. It is located in the new town of Changsha, pudding new area, Shanghai. Which officially opened on June 16, 2016.It is the first in mainland China, the third in Asia, and the sixth Disney theme park in the world. There are seven theme parks in the park: mickey street, fancy garden, adventure island, treasure bay, tomorrow world, dream world, toy mobile garden. There are also two theme hotels: Shanghai Disneyland hotel, toy story hotel and a subway station; Disney station. There are many global launch rides. Shanghai Disneyland is expected to receive more than 50 million visitors each year.

Therefore, how to ensure the safety of the life and property of tourists is an important work during the Disney World business. Now, with the popularization of computer and application, network communication technology and the rapid development of image compression processing technology, and combined with the latest biometric identification technology, can provide more security for Disneyland, advanced high-tech security solutions. 


\section{Face Recognition}

A complete face recognition system usually includes three main steps: face detection and tracking, feature extraction and selection, classification discrimination. Face recognition technology has 1:1 recognition and 1: $\mathrm{N}$ recognition of two application modes[4].

The system verifies the identity of the identified object, and finally gets the conclusion that "Yes/No" is a "1:1" application. Access control system is a typical confirmation application.

We answer the problem that is "who are you?" Identify an object in a set of people. The recognition system gives a queue in the template library that is arranged in a similar degree from high to low. Let's say 10,50 .If the identification object belongs to this queue, it is called the alignment success. Identification of the identity of an object requires human involvement. This is an application of "1: N". The public security photo comparison system belongs to this application mode [5].

\section{Application fields}

Biometric identification technology is the use of the human body itself inherent physical characteristics(such as fingerprint, palm print, iris, retina, face, DNA, etc.) and behavior characteristics(such as handwriting, sound, keystroke). The techniques of image processing or other digital signal processing techniques and pattern recognition are used to identify the technology of identity. He has the unique, stable, duplicable, non-counterfeit and other prominent features, which are more secure than traditional methods.

Face recognition is the basic function of human vision system and is also the most direct way to recognize each other. Therefore, it is an important research content in biometric identification. Compared with other biological features, it has a unique advantage in usability. Including: it can be concealed operation, it suitable for security, monitoring and escape, etc. It is non - contact signal acquisition, and is not invasive, no damage, easy to be accepted by people; Therefore, face recognition has broad potential application prospects in security, business, finance, human-computer interaction and other fields.

\section{Application Demands of Shanghai Disneyland}

Shanghai Disneyland opened in 2016 with a large number of tourists flocking to Shanghai Disneyland. In the current international counter-terrorism and the domestic fight against national separatism situation is very grim situation, we need use high-tech means to strengthen Disneyland all aspects of safety management, it is the urgent request of the people's life safety and maintenance. The public security organ in China has launched the "online pursuit" struggle, and has used the online listing to supervise the police. They posted photos, ids and features of the fugitives online. He then searches and compares the arrested suspect on the Internet to determine whether he is a fugitive wanted on the Internet. However, the judgment of this method should be verified by a variety of techniques manually, and there is a big difficulty in verifying the identification of the criminal suspect with fake or no identification documents. Using face recognition technology, we only need to photograph the human face, and then transmit the facial feature data to the computer center database through the computer network. The system can automatically compare the human face in the database, and make the identification quickly and accurately.

Population management, especially the management of floating population, is the basic work of the construction of "peace city". With the development of China's social economy and the increasing frequency of various economic activities, the floating population in Shanghai is increasing rapidly. At present, all kinds of counterfeit identification documents are rampant, and it is difficult to realize the anti-counterfeiting of identity documents by means of existing technologies. Biometric identification technologies, such as face recognition and the current public security household management has 
promote the use of the anti-counterfeiting machine-readable, the combination of the second generation id card in order to strengthen the floating population management provide strong technical support.

In addition to the public security, security, military, financial and other industrial markets, the demand for digital security and certified products based on face recognition in civil security is also huge. Through the extensive investigation, we found that the computer information system safety control, e-commerce, e-government, residential quarters, school access control is an urgent need to many aspects, such as identification technology with excellent properties to replace now generally used the user account/password/digital certificate model. According to the national institute of standards and technology (NIST)/federal information processing standards (FIPS), "while relying on passwords is a traditional method of identity authentication, the security of this approach is not satisfactory. In the current situation, more advanced, safer and more efficient certification methods are needed to meet the needs of all aspects of society.

\section{Face Recognition in Shanghai Disneyland}

The face recognition control system combines the video recording function of the intelligent monitoring system. It uses the efficient face detection function of the front end to identify the face in the back end with the object of the cloth control. Then it is found that the control is automatically sent to the alarm signal, and the final judgment is made by manual. In this way, face recognition can be used to support the corresponding security business needs, so as to achieve fast real-time tracking and find the effect of focusing on the image.

The System Structure

Mainly include a number of monitoring machines on the front end. It is generally close to the site of the booth, which can connect multiple cameras for face collection and video. Through the network, these front-end machines can connect with the remote control manager of the back end, and the face will be collected here for recognition and alarm processing.

The layout of the camera needs to be designed according to the situation, so as to obtain the highest quality face image.

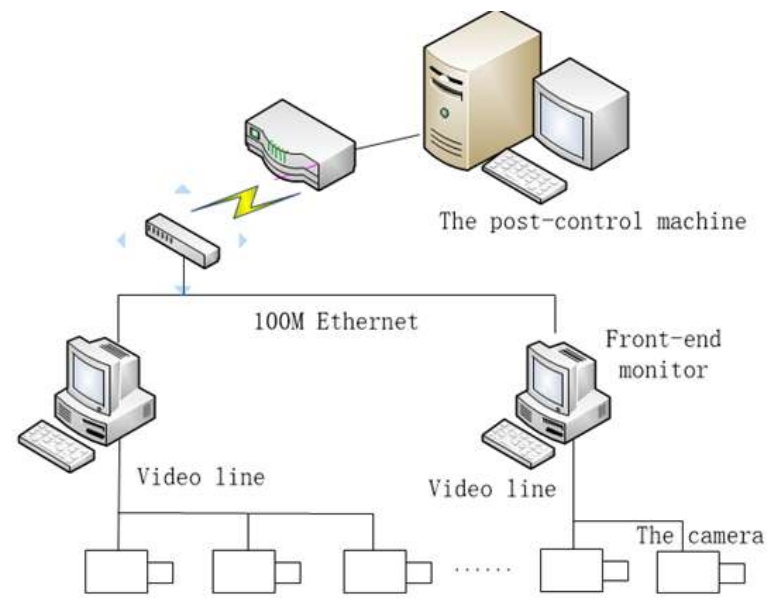

Figure 1 The System Structure

Applications

1) Real-time photo comparison; We can obtain the photos of the suspect by means of network transmission, live action, photo and other means. Then enter the computer and compare them to all the photos in the criminal's library. Using personnel to check the comparison system through similarity 
calculation generate the corresponding queue, can effectively find out from the hundreds of millions of photos of high similarity, so can greatly improve the efficiency.

2) It can support multi-clue combination constraint alignment, which can effectively improve the ratio of ratio. It can support unique features such as scar and mole alignment. With the function of lighting compensation and gray control, the success rate of comparison is greatly increased, and it can be compared with the photo construction, increasing the storage capacity and enriching the library resources.

3) It can support distributed data storage, which can effectively reduce the pressure of network bandwidth and storage capacity. It can support distributed multi-machine parallel modeling, which can greatly shorten the system construction cycle. At the same time, it can support multiple business mouth portrait library management. And it can support multiple remote transmission modes, including wireless, mobile phone photo transmission, etc.

\section{System Installation Orientation Selection}

The system consists of three parts: data acquisition subsystem, data storage subsystem and authentication subsystem. According to the different functions of each part and the different requirements of the installation environment, we will combine the specific situation of Disneyland and select the appropriate installation orientation.

1) Location selection of data acquisition subsystem

The subsystem is mainly used for the collection of raw data. In layman's terms, the facial features of all the people who might enter the world expo site were collected. The best location of the system installation is the ticket outlets. That's because most of the people who enter the park are visitors. They have to buy tickets to enter the pavilion.

2) Location selection of data storage subsystem

The subsystem is used to store all data collected by the data collection subsystem. In order to ensure the safety and integrity of the data and not to be considered disruptive, the subsystem should be installed at the highest level of security.

3) Verify the location selection of the authentication subsystem

The subsystem is the direct embodiment of the whole system function and is responsible for the certification of all personnel entering the pavilion and the park. Therefore, every entry to the pavilion and the park must be installed with a subsystem.

\section{Specific Implementation Data Acquisition}

The staff of the pavilion will conduct data entry according to the valid certificate. The exhibition staff must hold valid documents (such as id card, etc.) when purchasing tickets, and cooperate with the staff to complete the data collection. Due to the large number of visitors, the system works faster and more efficiently.

Specific requirements for data storage

The amount of data stored by the storage subsystem is very large, which raises a high requirement for storage capacity, and at the same time, data security and integrity must be considered. These problems can be solved by combining current advanced storage technologies such as RAID. On the other hand, the system has to handle so much data at the same time that the system load must be heavy. Therefore, a distributed system can be considered to alleviate the system's pressure.

\section{Conclusions}


The Face recognition technology has been applied in some provinces and cities in China. And it has achieved remarkable results, and will also play an important role in the future of Shanghai Disney and city monitoring. It can build and create a harmonious society and it also can make unique contributions.

\section{References}

[1] Hu X P, Chen D S , Chen W B . Design and implementation of face detection system on smart phone[J]. Computer Engineering and Design, 2010,31(3): 672-675.

[2] Chen Y N , Chen X G . A novel identify recognition system based on mobile phone and face recognition[J]. Computer Application Software, 2011,28(3): 77-79.

[3] Cao S . A fast SURF way for human face recognition with cell similarity[A]. 2011 6th IEEE Conference on Industrial Electronics and Applications (ICIEA)[C]. 2011. 166-169.

[4] Luo J , Shi Y X , Duan D Y . Face recognition method based on SIFT feature[J]. Computer Engineering, 2010,36(13): 173-174.

[5] Zhao R Z . Study on Face Recognition Based on Single-sample Training Set[D]. Chongqing:Chongqing University, 2012. 